\title{
Universiteit
}

Leiden

The Netherlands

\section{Economic allocation: examples and derived decision tree}

Guinée, J.B.; Heijungs, R.; Huppes, G.

\section{Citation}

Guinée, J. B., Heijungs, R., \& Huppes, G. (2004). Economic allocation: examples and derived decision tree. Retrieved from https://hdl.handle.net/1887/11426

Version: $\quad$ Not Applicable (or Unknown)

License: $\quad$ Leiden University Non-exclusive license

Downloaded from: https://hdl.handle.net/1887/11426

Note: To cite this publication please use the final published version (if applicable). 


\title{
LCA Methodology
}

\section{Economic Allocation: Examples and Derived Decision Tree}

\author{
Jeroen B. Guinée*, Reinout Heijungs and Gjalt Huppes \\ Institute of Environmental Sciences (CML), Leiden University, P.O. Box 9518, 2300 RA Leiden, The Netherlands
}

* Corresponding author $(\underline{\text { Guinee@cml.leidenuniv.nl })}$

\section{DOI: http://dx.doi.org/10.1065/lca2003.10.136}

\section{Abstract}

Goal, Scope and Background. In the recently published (Dutch) Handbook on LCA, economic allocation is advised as baseline method for most allocation situations in a detailed LCA. Although the Handbook on LCA aimed to provide a 'cookbook' with operational guidelines for conducting each step of an LCA, this was not completely achieved for the allocation step. The guidelines for allocation largely remained at the level of principles. This restricted elaboration of economic allocation may hamper application in practice. Therefore, this paper elaborates some examples applying economic allocation.

Method. Two concepts are of particular importance when applying economic allocation: functional flow and multi-functional process. The definitions of these concepts are presented and discussed. The basic principle of economic allocation is that having determined the various functional flows of a multi-functional process, all other flows need to be allocated to these functional flows according to their shares in the total proceeds. Proceeds are based on prices and these are not always easy to determine for a process. A summary of possible solutions for different problems when determining prices is given.

Results and Discussion. The examples presented focus on coproduction and various recycling situations. All examples are hypothetical in order to avoid discussions on the data. The examples show that the prices of the functional flows determine the allocation results. It is of importance to have correct information on the relative prices of the functional flows at stake, especially whether they are negative or positive. Learning from these examples, we establish a decision tree for economic allocation. The decision tree is meant for identifying and handling multi-functionality situations starting from a defined (product) system. This decision tree is with minor adaptations also applicable to other allocation methods and has a more general value than for the economic allocation method only.

Conclusions and perspective. The examples have helped us to establish a decision tree for handling the multi-functionality problem by economic allocation. The examples can be broadened to other materials and allocation situations. We would encourage others to provide other examples and experiences as we expect that these will help to further improve and refine the guidelines and decision tree for economic allocation in future.

Keywords: Allocation; aluminium; economic allocation; inventory analysis; life cycle assessment (LCA); multi-functionality; open-loop recycling

\section{Goal, Scope and Background}

Economic allocation is one recognised way of systematically executing allocation in LCA. ISO gives this option in step 3 of its allocation procedure (ISO 1998). However, how exactly this economic allocation is to be done has remained unspecified, or at least for many practitioners the choices to be made, and their consequences are still unclear. In the recently published Dutch Handbook on LCA (Guinée et al. 2002), we worked out the principles for economic allocation in a section dedicated to multi-functionality and allocation. ${ }^{1}$ In the Handbook, economic allocation is advised as baseline method for most allocation situations in a detailed LCA. In this method, for example, the share of each product in total sales of a process is considered to indicate its share in the full existence of that process.

Whereas the general ambition of the Handbook on LCA was to provide a 'cookbook' with operational guidelines for conducting each step of an LCA, this aim was not completely achieved for the allocation step; it remained at the level of principles. Due to this restricted elaboration of economic allocation step, it may hamper application in practice. Therefore, this paper elaborates some examples applying economic allocation according to the above mentioned Handbook on LCA. Learning from these examples, we establish a decision tree for economic allocation. This decision tree is - with minor adaptations - also applicable to other allocation methods and has a more general value than for the economic allocation method only.

The purpose of this paper is thus not to discuss economic allocation in all it appearances (e.g. Werner and Richter 2000; Vogtländer et al. 2001) but rather to illustrate one specific method of economic allocation - viz. economic allocation according to the Dutch Handbook on LCA - with educational examples. We don't discuss the uncertainties attached to this specific method in depth. As recommended in the Handbook sensitivity analyses always remain necessary for allocation, since it is impossible to have an ultimate best solution accepted by everybody for a problem that is an artefact of wishing to

\footnotetext{
${ }^{1}$ Multi-functionality indicates the problem that product systems under study often provide more functions than the one that is studied in the functional unit of interest. Allocation is one possible solution for this problem. Allocation can be sub-divided into partitioning (according to mass or according to economic proceeds, the latter being the subject of this paper) and substitution (see e.g. Weidema 2001). There are more solutions, however, such as accepting multi-functionality and modelling it as it is, or the pseudo-inverse (see Heijungs and Frischknecht 1998).
} 
isolate one function out of many. Sensitivity analyses as such are, however, not discussed further in this paper.

Below, the main principles of the economic allocation method will be explained briefly. Then illustrated examples of economic allocation will be given and a decision tree will be presented and discussed. Finally, some conclusions and recommendations will be drawn.

\section{Method: Economic Allocation}

For all more theoretical discussions on the pro's and con's of economic allocation as opposed to other allocation methods and in relation to ISO Guidelines, we here refer to the Handbook on LCA, in particular to Section 3.9 of Part 3. In this paper we will focus on economic allocation only and briefly describe its principles in practical terms, that is in the way it would be applied in practice.

For this, two basic prior definitions are important in particular:

- Functional flow: any of the flows of a unit process that constitute its goal, viz. the product outflows (including services) of a production process and the waste inflows of a waste treatment process. ${ }^{2}$

- Multi-functional process: a unit process yielding more than one functional flow, i.e. co-production, combined waste processing and recycling:

- Co-production: a multi-functional process having more than one functional outflow and no functional inflow.

- Combined waste processing: a multi-functional process having no functional outflow and more than one functional inflow.

- Recycling: a multi-functional process having one or more functional outflows and one or more functional inflows (including cases of combined waste processing and co-production simultaneously).

In the economic literature, multi-functional processes are referred to as joint or combined production (e.g. Koutsoyiannis 1980). In this article we will not distinguish between these two any further but deal with both under the heading of multifunctional processes. The Handbook on LCA distinguishes two steps in solving the multi-functionality problem. The first concerns the modelling of the product system studied in the inventory analysis. In this step system boundaries are set and processes are described and process flows quantified. In this step multi-functionality problems can be identified and the model of the product system is drafted. The better and more specific the model, the less multi-functionality problems will remain. For example, if the processes are specified to unit operation levels (e.g. individual machines), multi-functionality problems may be avoided in some specific cases. This is the starting step in the ISO allocation procedure.

The second step concerns solving the remaining multi-functionality problems. For this step, the Handbook on LCA proposes to systematically apply economic allocation, next to other ways of solving the multifunctionality problem as sensitivity analyses, and next to other ways, based on physico-chemical relations, for waste treatment processes.

\footnotetext{
2 Observe that a flow is not intrinsically a functional flow, but only with respect to a certain unit process. To be specific, an outflow that is a functional flow for one unit process is a non-functional inflow for one or more other unit processes, and an inflow that is a functional flow for a specific unit process is a non-functional outflow for one or more other unit processes.
}

In a practical study, one of the first things to be determined is which flows are the functional flows of a process. For this, the distinction between products and wastes is an essential step. To distinguish products from wastes, the economic value of flows is the determining property. A product is a flow between two processes with an economic value higher than or equal to zero, whereas a waste is a flow between two processes with an economic value smaller than zero. Functional flows are either products that are produced by a process or wastes that are treated by a process. The functional flows of a specific unit process are the product outflows and the waste inflows. So, to determine if for process A in Fig. 1, there is a multi-functionality problem, we need to know which of the three flows are functional flows. Flow 3 is not an economic flow, just because it doesn't connect two unit processes but goes directly from a unit process into the environment, e.g. the aquatic compartment. This is an environmental or elementary flow, and therefore no functional flow, so it creates no multi-functionality problems. Assuming flow 1 has no negative value, all depends on the value of flow 2. If the economic value of flow 2 is higher than or equal to zero as well there is a multi-functionality problem which needs to be tackled, e.g., by economic allocation. If the economic value of flow 2 is smaller than zero, there is no multi-functionality problem but the flow 2 should be traced down to a process that will manage this flow as waste. If such a process is not occurring, the flow should be considered as a flow that has been cut off for reasons of data unavailability.

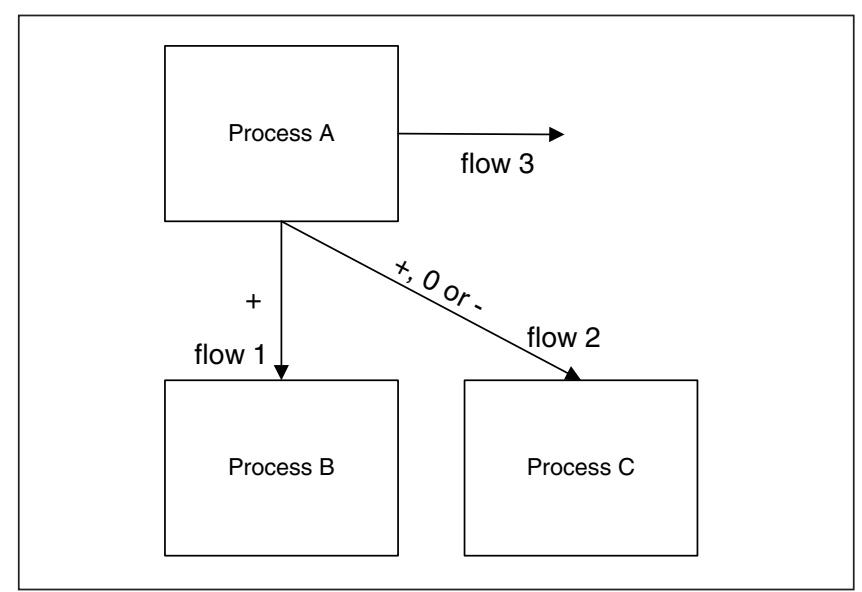

Fig. 1: Example of a potentially multi-functional process

The basic principle of economic allocation is that, having determined the various functional flows of a multi-functional process, all other flows need to be allocated to these functional flows according to their shares in the total proceeds. Proceeds are based on prices, and the price can be expressed in any currency such as $€$, US dollars or alike and the unit of flow can be quantified in any quantity and unit in which the prices are stated, such as piece, mass $(\mathrm{kg})$, energy $(\mathrm{MJ}$ or $\mathrm{kWh})$ or volume $\left(\mathrm{m}^{3}\right)$, as long as used consistently through one calculation (e.g. US dollars and $€$ shouldn't be used mixed in one calculation). In this method, the share of each product in total sales of a process is thus considered to indicate its share in the full existence of that process. The economic value created by a process is considered to be the driver of that process. 
Table 1: Strategies to find prices of products with missing or distorted markets

\begin{tabular}{|c|c|}
\hline Problem & Solution \\
\hline 1. Market prices not known & Look for public sources, preferably FOB (Free On Board) prices \\
\hline 2. $\quad$ Fluctuating prices & Use three-year averages, or use prices at futures market \\
\hline 3. Inflation & No problem, as long as the same base year is used in each process \\
\hline 4. $\quad$ Trends in real prices & No problem, as long as the same base year is used in each process \\
\hline 5. $\quad$ Different currencies in different processes & No problem, as long as the same currency is used in each process \\
\hline 6. $\quad$ Locally diverging prices & Choose prices at relevant process locations or calculate averages for the relevant region \\
\hline 7. $\quad$ Market prices available only further downstream & Gross sales value method, as worked out under '14' \\
\hline 8. $\quad$ Partially missing prices & Construct prices from costs and known prices \\
\hline 9. $\quad$ Economically based market distortions (e.g., Monopolies) & Use actual market prices, correct in very exceptional cases only \\
\hline 10. Regulations-based market distortions & Accept prices as they are, use value or cost of close alternative for missing market prices \\
\hline 11. Tax-like financing of activity (e.g., Sewer systems) & Treat as 'missing market, public provision' \\
\hline 12. Taxes and subsidies on products & Use the price the seller actually receives \\
\hline 13. Taxes and subsidies on activities & Do not correct for taxes and subsidies on activities. \\
\hline 14. In-firm prices not known & Use gross sales value method \\
\hline 15. Missing markets with public provision & Construct prices based on costs \\
\hline 16. Developing markets for recycling products & Use current prices of similar products to specify the price of future recycled products \\
\hline 17. Markets not yet in existence & Use expected future market prices \\
\hline
\end{tabular}

It is not always easy to determine the proceeds of a process. However, it are the shares in proceeds that need to be known and not the absolute values. This is also a solution to handling fluctuations. Prices may fluctuate considerably, but often the shares remain quite constant, particularly in the longer term. Long term average share is the relevant time horizon here in theory, although these data may often not be available. The uncertainties attached to these fluctuations are deemed important but not further discussed here. At first glance, we expect that the uncertainties of price fluctuations are comparable to uncertainties attached to other allocation methods as e.g. the physical quantities of functional flows of a particular multi-functional process also fluctuate (for instance, the amounts of milk and wool produced in sheep breeding will fluctuate per year, as will the prices of milk and wool).

For flows with missing or distorted markets, it may also be difficult to determine proceeds and shares. In the Dutch
Handbook on LCA attention has also been paid to such problems, and Table 1 shows in summary which solutions are proposed for different problems. For more details, we refer here to Guinée et al. (2002; Part 2b, 147-151).

Examples of how economic allocation works in practice are presented in the next section.

\section{Examples}

\subsection{Co-production}

In 1993, Huppes already proposed economic allocation as solution for multi-functionality problems in LCA studies (Huppes 1993). Fig. 2 shows an adapted version of the example used by Huppes on co-production of caustic soda, chlorine and hydrogen.

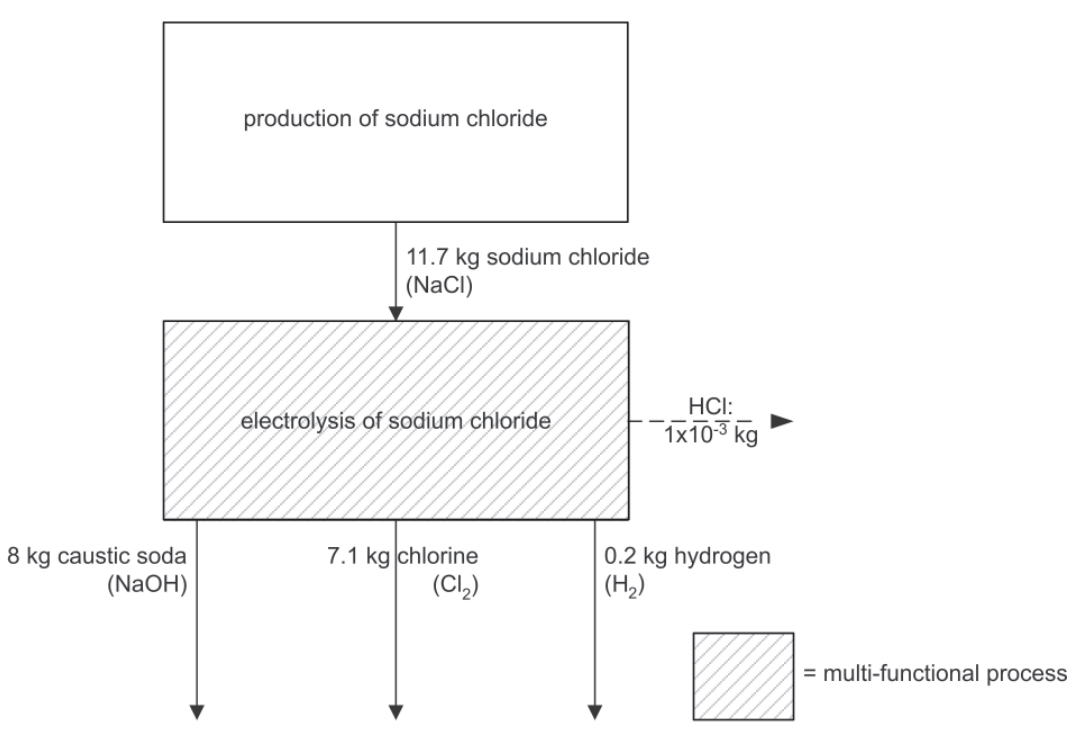

Fig. 2: Co-production process of caustic soda, chlorine and hydrogen (numbers are hypothetical) 
Table 2: Allocation factors for the electrolysis of sodium chloride

\begin{tabular}{l|c|c|c|c}
\hline Functional flow & Quantity & Price (€/unit) & Proceeds $(€)$ & Allocation factor \\
\hline $\mathrm{NaOH}$ (outflow; $\mathrm{kg})$ & 8 & 1.65 & 13.20 & $0.698(\alpha)$ \\
\hline $\mathrm{Cl}_{2}$ (outflow; $\mathrm{kg}$ ) & 7.1 & 0.80 & 5.68 & $0.301(\beta)$ \\
\hline $\mathrm{H}_{2}$ (outflow; $\left.\mathrm{kg}\right)$ & 0.2 & 0.10 & 0.02 & $0.001(\gamma)$ \\
\hline Total & - & - & 18.90 & 1.00 \\
\hline
\end{tabular}

Note that the numbers in this table are hypothetical and not meant to reflect any realistic values (roughly reflecting last year's prices).

Table 3: The unallocated multi-functional and the allocated mono-functional process data for the electrolysis of sodium chloride

\begin{tabular}{l|c|c|c|c}
\hline Flows & $\begin{array}{c}\text { Multi-functional } \\
\text { process }\end{array}$ & $\begin{array}{c}\text { Mono-functional } \\
\text { NaOH production }\end{array}$ & $\begin{array}{c}\text { Mono-functional } \\
\text { Cl }_{2} \text { production }\end{array}$ & $\begin{array}{c}\text { Mono-functional } \\
\mathbf{H}_{2} \text { production }\end{array}$ \\
\hline $\mathrm{NaCl}$ (nf inflow; $\mathrm{kg}$ ) & -11.7 & $0.698(\alpha) \times-11.7=-8.17$ & $0.301(\beta) \times-11.7=-3.52$ & $0.001(\gamma) \times-11.7=-0.01$ \\
\hline $\mathrm{HCl}$ (nf outflow; $\mathrm{kg}$ ) & $1 \times 10^{-3}$ & $0.698(\alpha) \times 1 \times 10^{-3}=6.98 \times 10^{-4}$ & $0.301(\beta) \times 1 \times 10^{-3}=3.01 \times 10^{-4}$ & $0.001(\gamma) \times 1 \times 10^{-3}=1 \times 10^{-6}$ \\
\hline $\mathrm{NaOH}$ (f outflow; $\mathrm{kg})$ & 8 & 8 & 0 & 0 \\
\hline $\mathrm{Cl}_{2}$ (f outflow; $\mathrm{kg}$ ) & 7.1 & 0 & 7.1 & 0 \\
\hline $\mathrm{H}_{2}$ (f outflow; $\mathrm{kg}$ ) & 0.2 & 0 & 0 & 0.2 \\
\hline
\end{tabular}

$\mathrm{Nf}=$ non-functional; $\mathrm{f}=$ functional; note that inflows are distinguished from outflows by a minus sign, hence -11.7 for $\mathrm{NaCl}$.

The functional flows are caustic soda $(\mathrm{NaOH})$, chlorine $\left(\mathrm{Cl}_{2}\right)$ and hydrogen $\left(\mathrm{H}_{2}\right)$. Assuming the quantities, prices and proceeds stated in Table 2, allocation factors can be calculated; these are referred to here as $\alpha, \beta$ and $\gamma$.

Emissions need to be allocated, i.c. $\mathrm{HCl}\left(1 \times 10^{-3} \mathrm{~kg}\right)$, but also other non-functional flows, i.c. sodium chloride use $(11.7 \mathrm{~kg})$ need to be allocated to the three functional flows:

This table clearly shows that functional flows are being allocated to and not allocated themselves: all non-functional flows are allocated to the functional flows only. It also shows that the $100 \%$ rule counts for economic allocation: for each flow, the quantities of the mono-functional processes together precisely constitute the original quantity of the multi-functional processes for that specific flow. Of final interest is that one should distinguish between the allocation of a multi- functional process and the ratios in which mono-functional processes participate in each of the separated systems. Fig. 3 illustrates how the multi-functional electrolysis process can be allocated into three different mono-functional processes, each connected to one and the same mono-functional upstream process.

\subsection{Two cases of open-loop recycling}

A co-production process is simple enough to understand the economic allocation procedure. Recycling processes, however, often create more problems, both conceptually and mathematically. Therefore, we now present four recycling examples starting with two nearly identical cases on open-loop recycling examples for aluminium. The examples are fully hypothetical, and thus cannot be copied into any LCA case

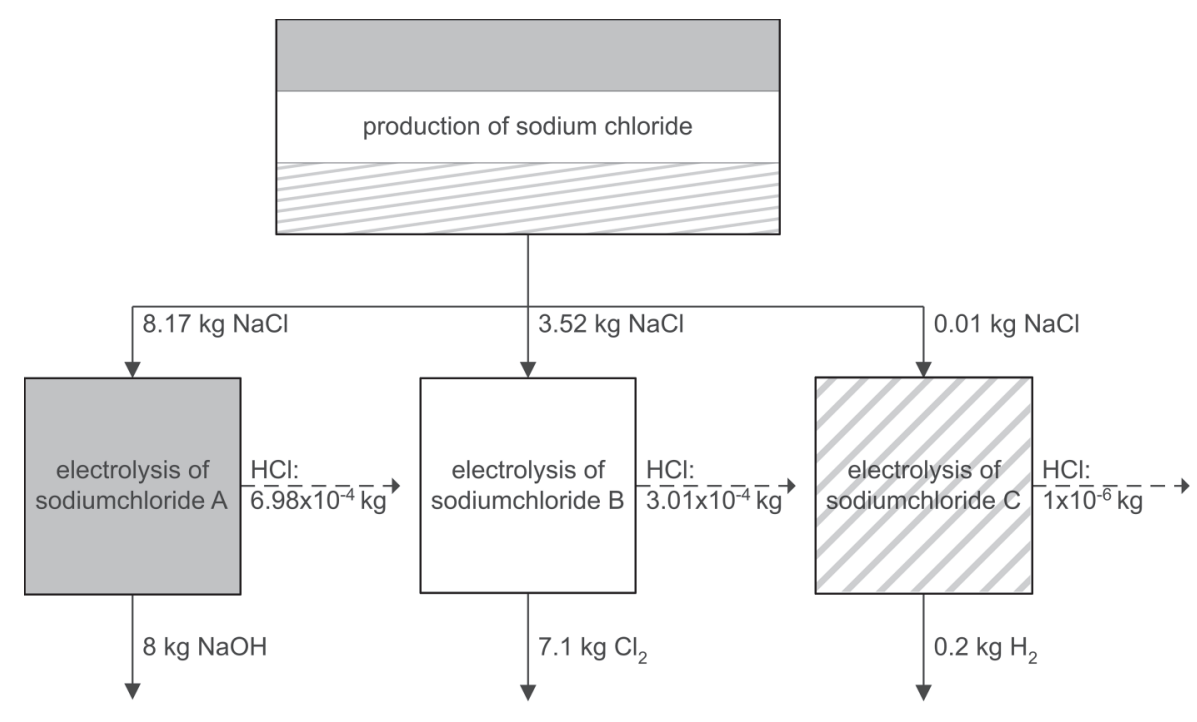

Fig. 3: Allocated example on co-production of caustic soda, chlorine and hydrogen 


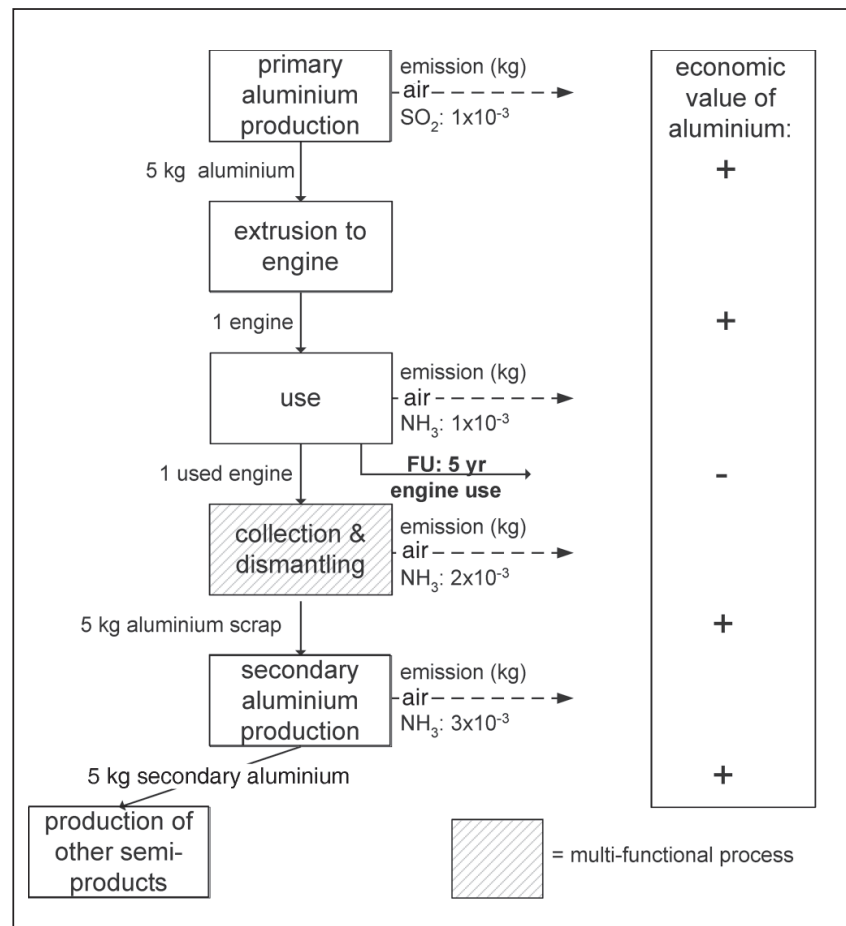

Fig. 4: Hypothetical example on open-loop recycling (first case of section 3.2)

study. The calculations have been made with CMLCA, and the data files can be downloaded from our website (http:// www.leidenuniv.nl/cml/ssp/software/cmlca/index.html).

Fig. 4 shows the first hypothetical open-loop example. There are two processes in this system that need a closer look at: the 'use' process and the 'collection $\&$ dismantling' process. The 'use' process has two outflows of which only one is a functional flow (i.c. product): the functional unit ' 5 years engine use'. The other outflow 'used engine' has a negative value and is thus a waste flow which should be traced down to it waste management process, i.c. 'secondary aluminium production'. The inflow 'engine' is a product, hence this is not a functional flow. The 'collection \& dismantling' process provides a turning point for the economic value of the used engine and aluminium scrap flows and thus we have an example of a multi-functional process, in this case a recycling process. As the resulting secondary aluminium is used in other products than the original engine, it is a question of open-loop recycling. Thus the process 'collection \& dismantling' needs to be partly allocated to the system of the engine (system 1) and partly to the system using the aluminium scrap (system 2). Assuming the quantities, prices and proceeds stated in Table 4, allocation factors can again be calculated.

In this 'collection \& dismantling' process, only one emission is at stake: $\mathrm{NH}_{3}$ to air. This emission needs to be allocated to the aluminium scrap (part of system 2) and used engine (part of system 1 ) as shown in Table 5.

The total emissions follow from Fig. 5. For $\mathrm{SO}_{2}$ for system 1 , the emission thus equals $1 \cdot 10^{-3} \mathrm{~kg}$ and for system 2 equals $0 \mathrm{~kg}$. The total emission of $\mathrm{NH}_{3}$ for system 1 thus equals $1 \cdot 10^{-3}+0.8 \cdot 10^{-3}=1.8 \cdot 10^{-3} \mathrm{~kg}$, and for system 2 equals $1.2 \cdot 10^{-3}+3 \cdot 10^{-3}=4.2 \cdot 10^{-3} \mathrm{~kg}$.

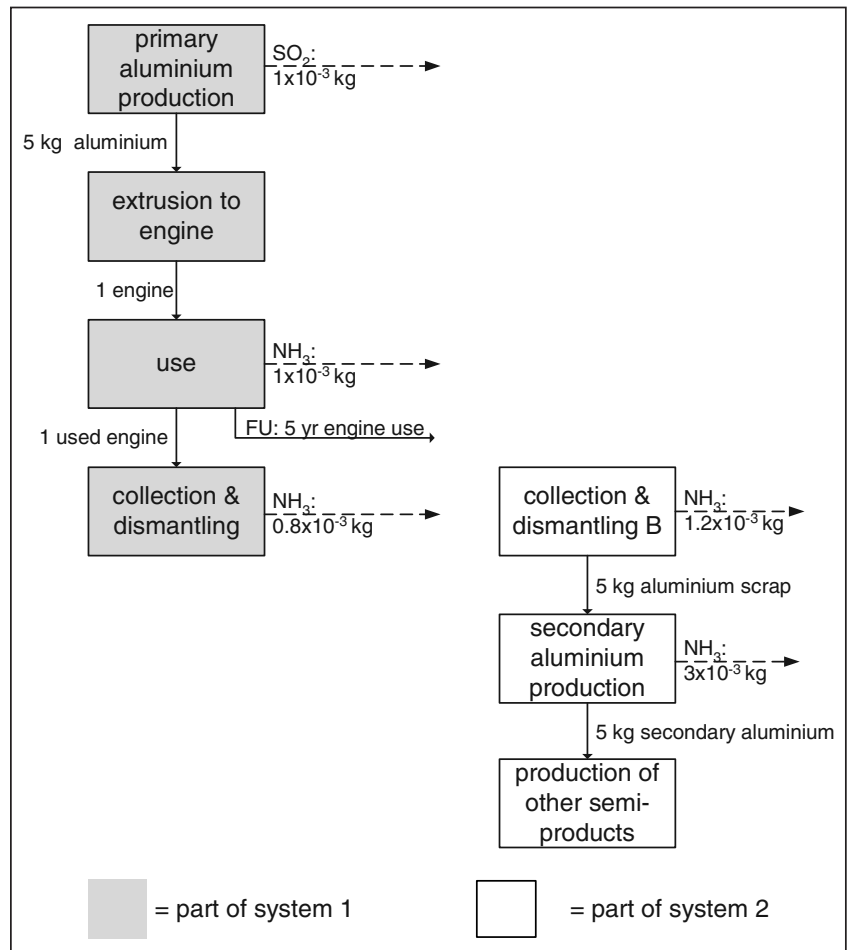

Fig. 5: Allocated hypothetical example on open-loop recycling (first case of section 3.2)

Table 4: Allocation factors for the collection \& dismantling of used engines

\begin{tabular}{l|c|c|c|c}
\hline Functional flow & Quantity & Price (€/unit) & Proceeds (€) & Allocation factor \\
\hline Used engine (inflow; $p$ ) & -1 & -100 & 100 & $0.4(\alpha)$ \\
\hline Aluminium scrap (outflow; kg) & 5 & 30 & 150 & $0.6(\beta)$ \\
\hline Total & - & - & 250 & 1 \\
\hline
\end{tabular}

Table 5: The unallocated multi-functional and the allocated mono-functional process data for the collection \& dismantling of used engines

\begin{tabular}{l|c|c|c}
\hline Flows (hypothetical) & Multi-functional process & $\begin{array}{c}\text { Mono-functional waste } \\
\text { management of used engine }\end{array}$ & $\begin{array}{c}\text { Mono-functional production of } \\
\text { aluminium scrap }\end{array}$ \\
\hline $\mathrm{NH}_{3}$ (nf outflow; $\mathrm{kg}$ ) & $2 \cdot 10^{-3}$ & $0.4(\alpha) \times 2 \cdot 10^{-3}=0.8 \cdot 10^{-3}$ & $0.6(\beta) \times 2 \cdot 10^{-3}=1.2 \cdot 10^{-3}$ \\
\hline Aluminium scrap (f outflow; $\mathrm{kg}$ ) & 5 & 0 & 5 \\
\hline Used engine (f inflow; $p$ ) & -1 & -1 & 0 \\
\hline
\end{tabular}

$\mathrm{Nf}=$ non-functional; $\mathrm{f}=$ functional 


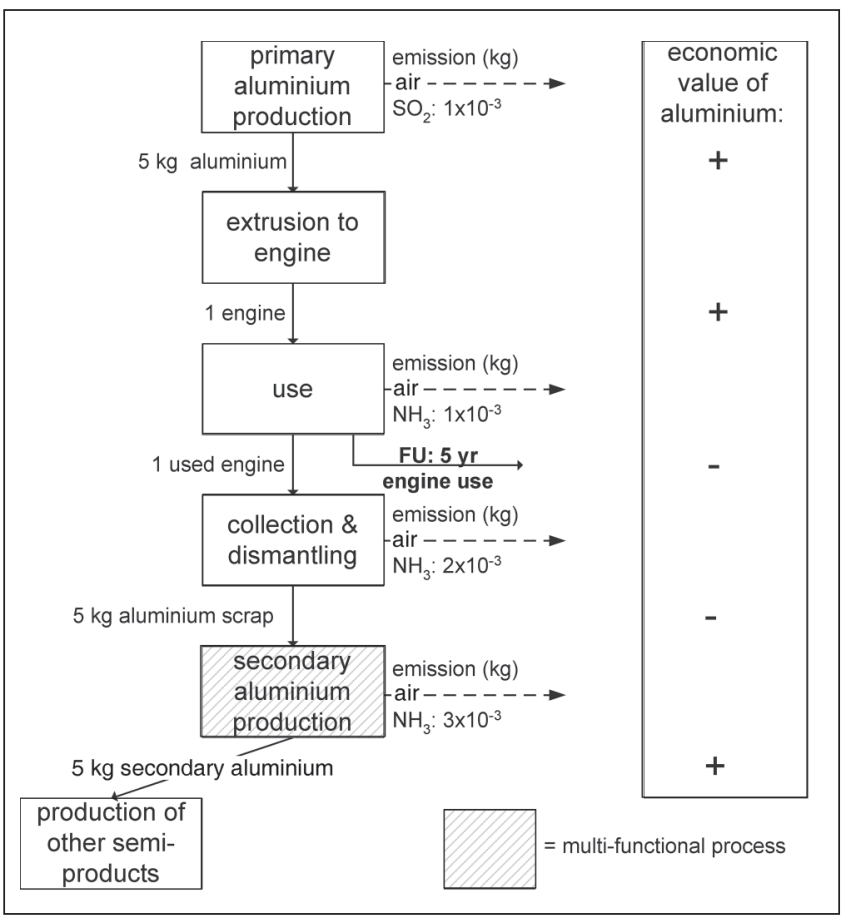

Fig. 6: Hypothetical example on open-loop recycling (second case of section 3.2)

Now let us look at the second hypothetical open-loop example, which is a slightly different version of the first, see Fig. 6.

Now not only the flow 'used engine' but also the flow 'aluminium scrap' is negatively valued and is thus a waste flow which should be traced down to its waste management process, i.e. 'secondary aluminium production'. In this case, the 'secondary aluminium production' process provides a turning point for the economic value of the aluminium scrap and the secondary aluminium flows and as the latter is used in other product systems, we have an example of open-loop recycling again. Now, the process 'secondary aluminium production' needs to be partly allocated to the aluminium scrap (part of system 1) and partly to secondary aluminium (part of sys- tem 2). Assuming the quantities, prices and proceeds stated in Table 6, allocation factors can again be calculated.

In this process, 'secondary aluminium production', again just one emission is at stake: $\mathrm{NH}_{3}$ to air. This emission needs to be allocated to the aluminium scrap (part of system 1) and the secondary aluminium (part of system 2) as shown in Table 7.

The total emissions follow from Fig. 7. For $\mathrm{SO}_{2}$ for system 1 , the emission thus equals $1 \cdot 10^{-3} \mathrm{~kg}$ and for system 2 equals $0 \mathrm{~kg}$. The total emission of $\mathrm{NH}_{3}$ for system 1 thus equals $1 \cdot 10^{-3}+2 \cdot 10^{-3}+1.5 \cdot 10^{-3}=4.5 \cdot 10^{-3} \mathrm{~kg}$, and for system 2 equals $1.5 \cdot 10^{-3} \mathrm{~kg}$.

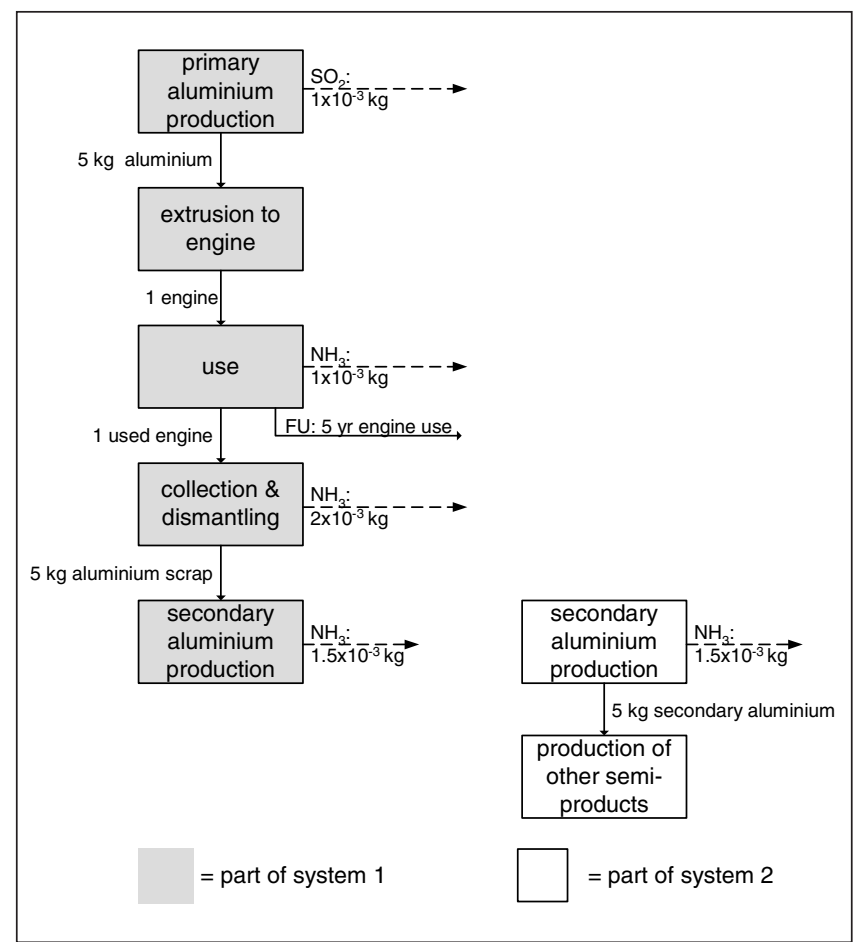

Fig. 7: Allocated hypothetical example on open-loop recycling (second case of section 3.2)

Table 6: Allocation factors for the secondary aluminium production

\begin{tabular}{l|c|c|c|c}
\hline Functional flow & Quantity & Price $(\boldsymbol{\epsilon} / \mathbf{k g})$ & Proceeds $(\boldsymbol{\epsilon})$ & Allocation factor \\
\hline Aluminium scrap (inflow; kg) & -5 & -30 & 150 & $0.5(\alpha)$ \\
\hline Secondary aluminium (outflow; kg) & 5 & 30 & 150 & $0.5(\beta)$ \\
\hline Total & - & - & 300 & 1 \\
\hline
\end{tabular}

Table 7: The unallocated multi-functional and the allocated mono-functional process data for the secondary aluminium production

\begin{tabular}{l|c|c|c}
\hline Flows (hypothetical) & $\begin{array}{c}\text { Multi-functional } \\
\text { process }\end{array}$ & $\begin{array}{c}\text { Mono-functional waste management } \\
\text { of aluminium scrap }\end{array}$ & $\begin{array}{c}\text { Mono-functional production } \\
\text { of secondary aluminium }\end{array}$ \\
\hline $\mathrm{NH}_{3}$ (nf outflow; $\mathrm{kg}$ ) & $3 \cdot 10^{-3}$ & $0.5(\alpha) \times 3 \cdot 10^{-3}=1.5 \cdot 10^{-3}$ & $0.5(\beta) \times 3 \cdot 10^{-3}=1.5 \cdot 10^{-3}$ \\
\hline Aluminium scrap (f inflow; $\mathrm{kg}$ ) & -5 & -5 & 0 \\
\hline Secondary aluminium (f outflow; $\mathrm{kg}$ ) & 5 & 0 & 5 \\
\hline $\mathrm{Nf}=$ non-functional; $\mathrm{f}$ =functional & & \\
\hline
\end{tabular}




\subsection{Closed-loop recycling}

The two cases on open-loop recycling may be expanded to cover closed-loop recycling as well. For this, we modified the system a little bit and that gives a new multi-functionality situation (Fig. 8).

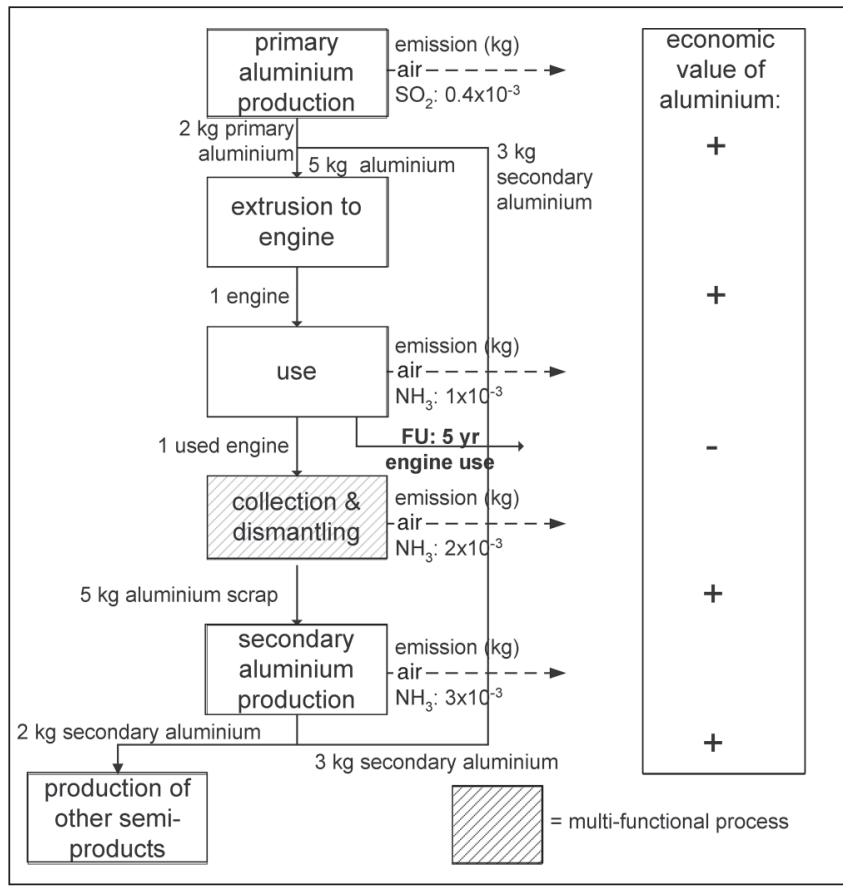

Fig. 8: Hypothetical example on closed loop-recycling (section 3.3)
The system in Fig. 8 is comparable to Fig. 4, except that part of the secondary aluminium is now also used by the engine system (system 1) resulting in a situation of openloop recycling combined with closed-loop recycling. Similar to Fig. 4 , the process 'collection $\&$ dismantling' needs to be partly allocated again to the used engine (part of system 1) and partly to the aluminium scrap (part of system 2). In addition, there is a unit process, secondary aluminium production, that has an output of $5 \mathrm{~kg}$ of secondary aluminium, of which $3 \mathrm{~kg}$ goes back to system 1 and $2 \mathrm{~kg}$ goes to system 2 . This is not a co-production process (only one functional flow!), and there is no allocation needed for this process. Assuming the same prices as in Table 5, the same allocation factors $\alpha=0.4$ and $\beta=0.6$ are obtained.

The emission of $\mathrm{NH}_{3}$ to air needs to be allocated to the aluminium scrap (part of system 2) and used engine (part of system 1) in the same way as for the first recycling example (see Table 5).

The total emissions follow from Fig. 9. For $\mathrm{SO}_{2}$ for system 1, the emission equals $0.4 \cdot 10^{-3} \mathrm{~kg}$ and for system 2 again $0 \mathrm{~kg}$. The total emission of $\mathrm{NH}_{3}$ for system 1 thus equals $1 \cdot 10^{-3}+$ $0.8 \cdot 10^{-3}+3 / 5 \times 1.2 \cdot 10^{-3}+3 / 5 \times 3 \cdot 10^{-3}=4.32 \cdot 10^{-3} \mathrm{~kg}$, and for system 2 equals $2 / 5 \times 1.2 \cdot 10^{-3}+2 / 5 \times 3 \cdot 10^{-3}=1.68 \cdot 10^{-3} \mathrm{~kg}$.

\subsection{Pseudo-recycling: a form of co-production}

Finally, we modified the same system a little bit again, resulting in another multi-functionality situation (Fig. 10). Here it is assumed that aluminium is such a valuable material that all products in the material cascade have a positive value;

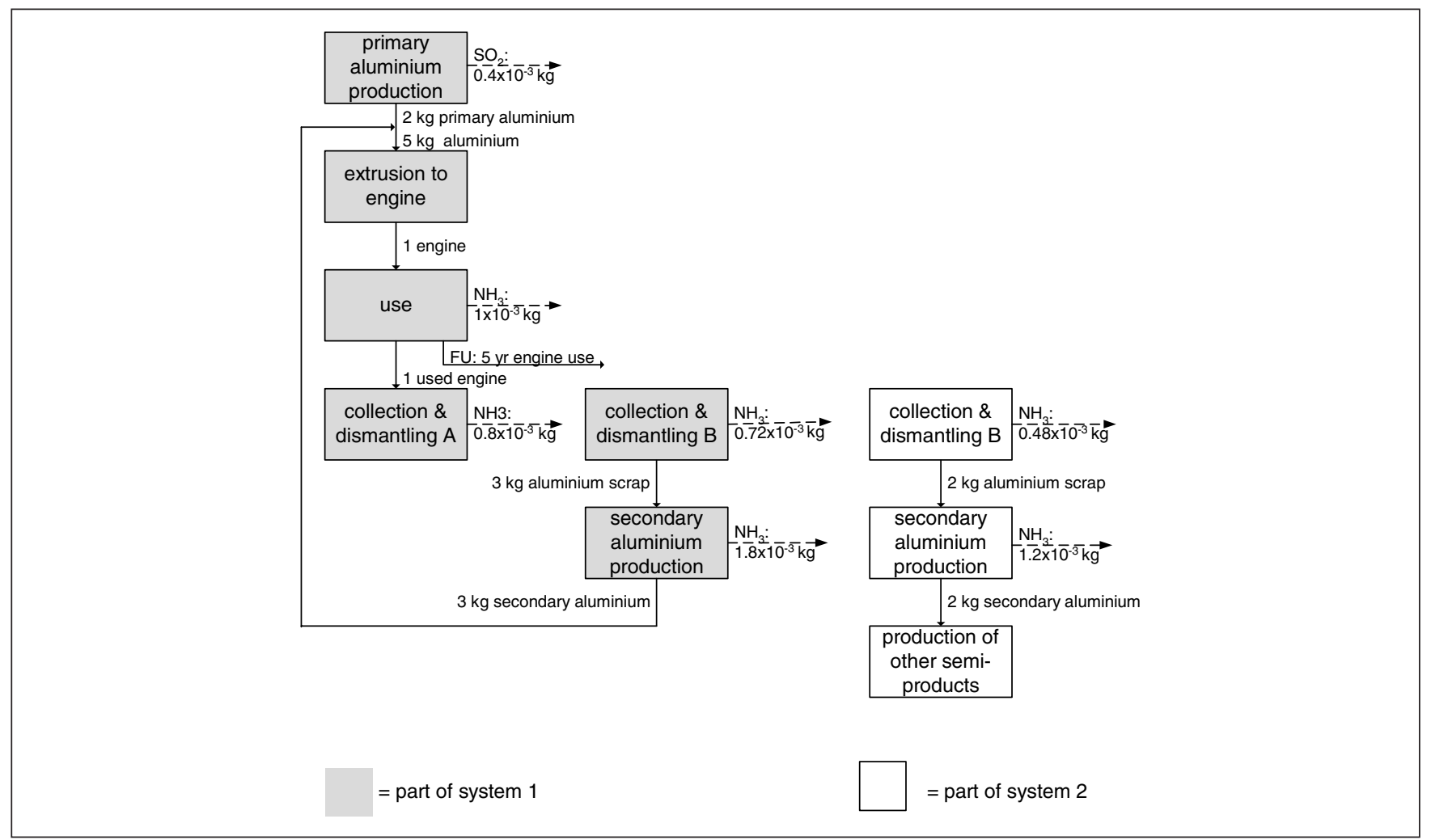

Fig. 9: Allocated hypothetical example on closed loop-recycling (section 3.3) 


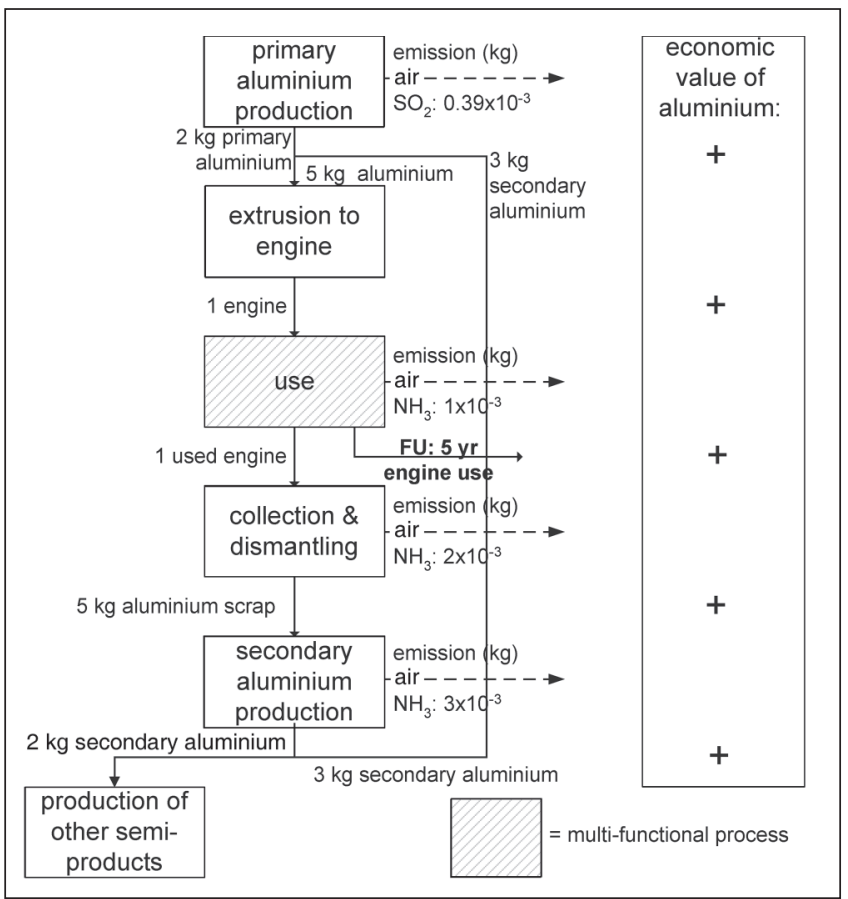

Fig. 10: Hypothetical example on pseudo-recycling (section 3.4)

even used engines and then of course also aluminium scrap. As a consequence, the use process is to be treated as a coproduction process, and there is no formal recycling process, even though a flow of secondary aluminium is informally perceived as a flow of recycled material. We have used the term 'pseudo-recycling' to distinguish it from the true cases of recycling described in 3.2 and 3.3. The use process is now a multi-functional process, delivering the functional flows engine use and used engine. Consequently, the values of these two flows form the basis for the allocation. Observe that also in this case, the secondary aluminium production is not a co-production process and that no allocation is needed for this process.

Assuming the quantities, prices and proceeds stated in Table 8, allocation factors can again be calculated.

In this case, the allocation is more complex although similar to the situation described in Section 3.1. The multi-functional proc- ess is the co-production of 5 years engine use and 1 used engine. The allocation for this process is summarised in Table 9.

The full details of the calculation are now much more difficult than in the previous case. Consider system 1: engine use. It includes a certain amount of aluminium, part of which is from secondary aluminium production. This process, on its turn, is fed by the allocated part of the use process that produces the used engine. In other words, although the allocation step of the use process separates the delivery of the engine use function from the production of used engines, the closed-loop recycling re-establishes the link between those two allocated processes (Fig. 11). But the two allocated processes cannot simply be merged into the original multi-functional process. ${ }^{3}$ The ratios of use of the two allocated proc-

${ }^{3}$ Note that for 5 years engine use it appears that not 1 but only 0.96 engine is needed. This is due to the multi-functional character of this process, as 0.04 engine is allocated to system 2 producing $2 \mathrm{~kg}$ of secondary aluminium.

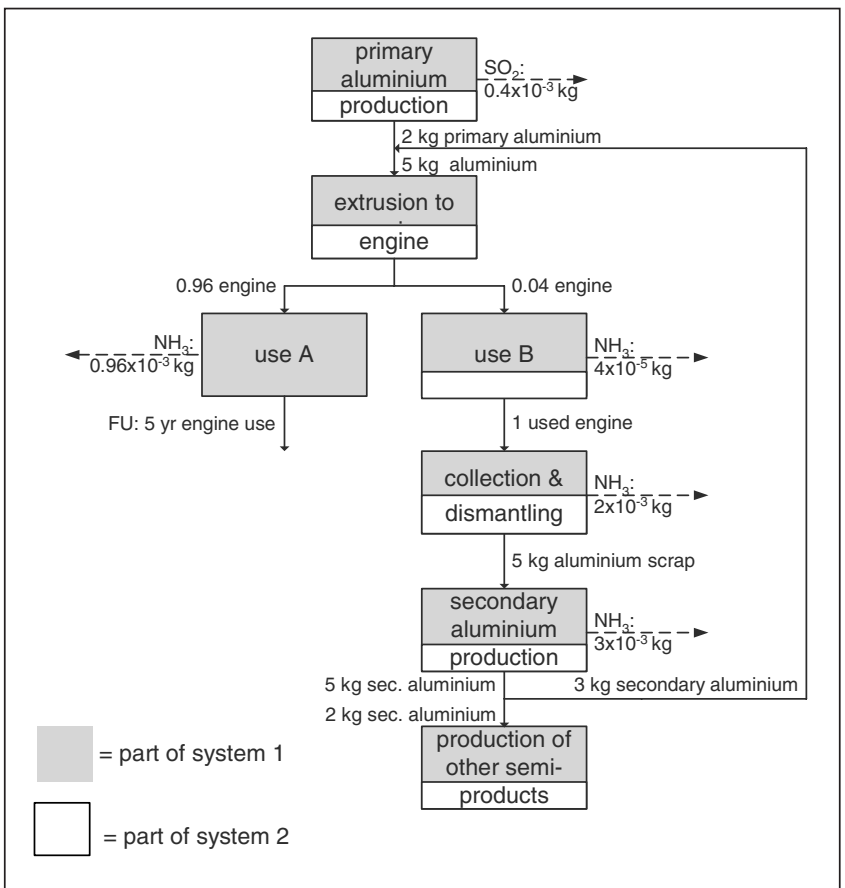

Fig. 11: Allocated but not yet separated hypothetical example on pseudorecycling (section 3.4)

Table 8: Allocation factors for the use process

\begin{tabular}{l|c|c|c|c}
\hline Functional flow & Quantity & Price (€/unit) & Proceeds $(€)$ & Allocation factor \\
\hline Engine use (outflow; $y r)$ & 5 & 500 & 2500 & $0.96(\alpha)$ \\
\hline Used engine (outflow; $p)$ & 1 & 100 & 100 & $0.04(\beta)$ \\
\hline Total & - & - & 2600 & 1 \\
\hline
\end{tabular}

Table 9: The unallocated multi-functional and the allocated mono-functional process data for the use process

\begin{tabular}{l|c|c|c}
\hline Flows (hypothetical) & Multi-functional process & Mono-functional $\mathbf{5}$ yr engine use & Mono-functional production of used engine \\
\hline $\mathrm{NH}_{3}$ (nf outflow; $\mathrm{kg}$ ) & $1 \cdot 10^{-3}$ & $0.96(\alpha) \times 1 \cdot 10^{-3}=9.6 \cdot 10^{-4}$ & $0.04(\beta) \times 1 \cdot 10^{-3}=4.0 \cdot 10^{-5}$ \\
\hline Engine (nf inflow; $p$ ) & -1 & $0.96(\alpha) \times-1=-0.96$ & $0.04(\beta) \times-1=-0.04$ \\
\hline Engine use (f outflow; $\mathrm{yr}$ ) & 5 & 5 & 0 \\
\hline Used engine (f outflow; $p$ ) & 1 & 0 & 1 \\
\hline $\mathrm{Nf}=$ non-functional; $f=$ functional
\end{tabular}




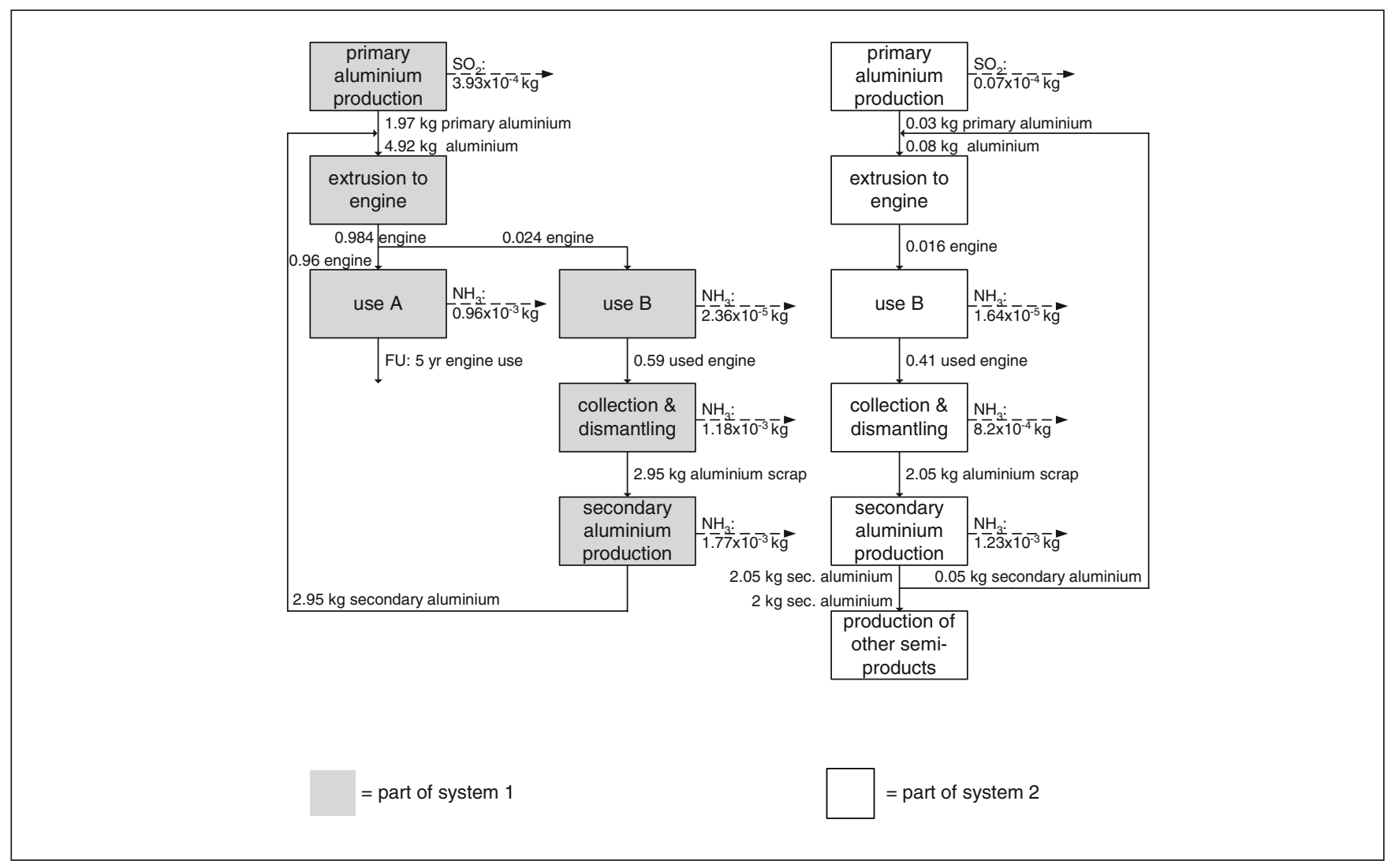

Fig. 12: Allocated and separated hypothetical example on pseudo-recycling (section 3.4)

esses differs per system. The consequence of the linkage is that the system now is a really circular one, for which a straightforward calculation is no longer applicable. Instead, the mutual and circular dependency calls for the solution of a set of simultaneous equations, for instance by means of matrix algebra; see Heijungs and Suh (2002) for more details. The results of such a calculation are represented in Fig. 12: for 5 years of engine use (system 1) the emission of $\mathrm{NH}_{3}$ is $3.93 \cdot 10^{-3} \mathrm{~kg}$, and the emission of $\mathrm{SO}_{2}$ is $0.393 \cdot 10^{-3} \mathrm{~kg}$, and for the production of $2 \mathrm{~kg}$ secondary aluminium (system 2) the emission of $\mathrm{NH}_{3}$ is $2.07 \cdot 10^{-3} \mathrm{~kg}$, and the emission of $\mathrm{SO}_{2}$ is $0.007 \cdot 10^{-3} \mathrm{~kg}$.

\section{Results and Discussion}

The four examples in sections 3.2, 3.3 and 3.4 demonstrate that the prices of the flows within a system may have quite some effect on the emissions that are allocated to a system.
The results are not directly comparable, because the situations are not exactly comparable. Table 10 summarises the most distinguishing features between the four cases.

Notice that the sum of the $\mathrm{NH}_{3}$-emissions allocated to system 1 and 2 is always equal to that of the unallocated system: $6 \cdot 10^{-3} \mathrm{~kg}$. The $100 \%$-rule does not only apply to the process level, but also to the system level.

One may compute the $\mathrm{NH}_{3}$-emission allocated to each of the systems as a function of the price of one of the flows. Fig. 13 show the results of the example of sections 3.3 and 3.4 for a range of prices of the used engine, all other data and prices kept constant, for system 1.

We see that, although the $\mathrm{NH}_{3}$-emission varies, there is no jump around the zero-price. Despite the fact that the allocated systems (see Fig. 9 and Fig. 12) are quite different in a qualitative sense, the mechanism of using proceeds-based allocation factors ensures that the small difference between

Table 10: Main differences in the set-up of the four examples

\begin{tabular}{|c|c|c|c|c|}
\hline Example & 1 (first case of section 3.2 ) & 2 (second case of section 3.2 ) & 3 (section 3.3) & 4 (section 3.4) \\
\hline Multi-functional process & Collection \& dismantling & Secondary aluminium production & Collection \& dismantling & Use \\
\hline Recycling & Open-loop & Open-loop & Closed-loop & No (pseudo) \\
\hline Price of used engine & Negative & Negative & Negative & Positive \\
\hline Price of aluminium scrap & Positive & Negative & Positive & Positive \\
\hline $\begin{array}{l}\mathrm{NH}_{3} \text {-emission allocated to } \\
\text { system } 1 \text { (engine use; kg) }\end{array}$ & $1.8 \cdot 10^{-3}$ & $4.5 \cdot 10^{-3}$ & $4.32 \cdot 10^{-3}$ & $3.93 \cdot 10^{-3}$ \\
\hline $\begin{array}{l}\mathrm{NH}_{3} \text {-emission allocated } \\
\text { to system } 2 \\
\text { (secondary aluminium; } \mathrm{kg} \text { ) }\end{array}$ & $4.2 \cdot 10^{-3}$ & $1.5 \cdot 10^{-3}$ & $1.68 \cdot 10^{-3}$ & $2.07 \cdot 10^{-3}$ \\
\hline
\end{tabular}




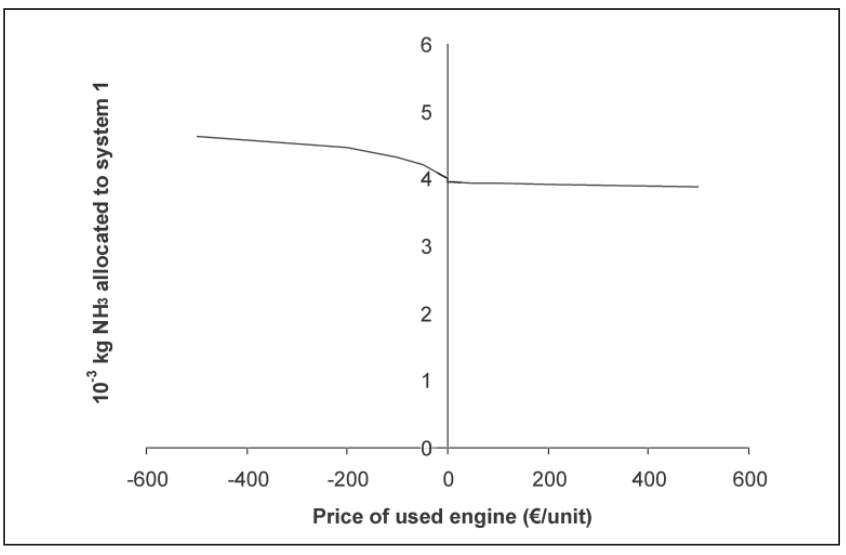

Fig. 13: $\mathrm{NH}_{3}$ allocated to system 2 as a function of the price of the used engine

a small positive and a small negative price leads to results that are only slightly different.

Based on the experiences with these examples, we have drafted a decision tree for handling the multi-functionality problem (Fig. 14). Although we concentrate on economic allocation, the decision tree can with small changes be used for more general situations, as the main part of the decision tree is about identifying functional flows and multi-functional processes. One should note that economic criteria are used for identifying functional flows, even when mass- or energy-based allocation is chosen. We would advocate the same for substitution.

The decision tree is meant for identifying and handling multifunctionality situations starting from a defined (product) system. The latter is important as only a defined (product) system will give the opportunity to identify multi-functionality situations and will already supply all inflow related processes upstream and e.g. waste management related processes downstream. The decision tree doesn't intend to help the LCA-practitioner with these system definition related issues, but is only meant to identify and help solving multi-functionality problems.

In step 1 of Fig. 14, the functional flows of each process of the system studied are identified. There are two types of functional flows: products produced and wastes to be treated. Products produced are outflows with economic value higher than or equal to zero, while wastes to be treated are inflows of a (waste managing) process with negative economic value, therefore providing proceeds for that process.
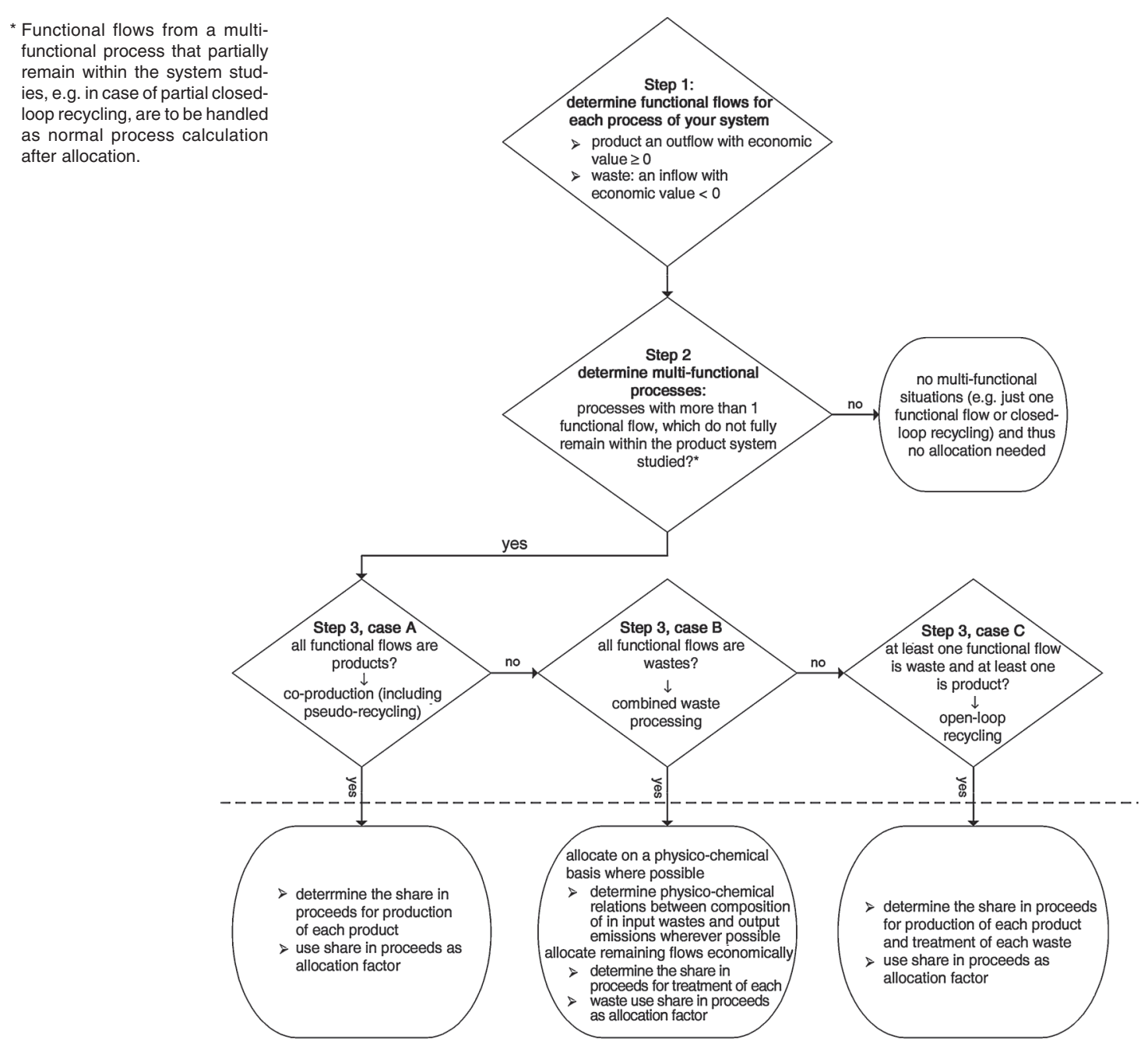

Fig. 14: Decision tree for identifying and handling multi-functionality situations 
In step 2 the multi-functional processes are determined by identifying those processes that have more than 1 functional flow, of which at least one is not used to its full quantity within the product system studied. Especially in the case of closed-loop recycling all functional flows remain within the system studied in their full quantities and allocation is thus not needed.

In step 3 the type of multi-functional situation is identified for each of the multi-functional processes. First, one should identify if all functional flows are products according to the definition of products given above. If that is the case, it is an example of co-production (case A) for which the following allocation procedure holds:

- determine the share in proceeds for production of each product;

- use share in proceeds as allocation factor.

From section 3.4 , remember to include cases of pseudo-recycling where positively valued 'waste' is upgraded to a higher valued secondary material.

If not all functional flows are products, one should identify if all functional flows are wastes according to the definition of wastes given above. If that is the case (case B), it is an example of combined waste processing for which the following allocation procedure holds:

- allocate on a physico-chemical basis where possible, here not further treated; see Handbook on LCA (Guinée et al. 2002);

- allocate remaining flows economically

- determine the share in proceeds for treatment of each waste;

- use share in proceeds as allocation factor.

Note that this procedure is not fully economic allocation, but also involves a portion of allocation on a physico-chemical basis as a first step. The latter has not been illustrated in the examples above.

If not all functional flows are products or wastes but there is a mix of at least one product and one waste (case C), the multifunctionality problem at stake is an example of recycling. If the product produced is used (partly or entirely) outside the system studied, we have an example of open-loop recycling for which the following allocation procedure holds:

- allocate on a physico-chemical basis where possible, here not further treated ${ }^{4}$;

- allocate remaining flows economically

- determine the share in proceeds for production of each product and treatment of each waste;

- use share in proceeds as allocation factor.

If a situation of both closed-loop and open-loop recycling is at stake for one process (see example in Section 3.3), the closedloop situation can be handled as a normal flow balancing after the open-loop recycling procedure has been applied.

Note again that this decision tree is, with some minor adaptations, also applicable to other allocation methods. Until the dashed line in Fig. 14, the decision tree has a general value. Below the dashed line, the text referring to economic allocation would of course be different for other methods.

\footnotetext{
4 This situation is not treated in the Handbook on LCA (Guinée et al. 2002). However, it may be applicable in cases like the incineration of a $\mathrm{Cd}$ containing plastic with energy recovery where the $\mathrm{Cd}$ emission could be allocated entirely to the Cd-containing plastic waste.
}

\section{Conclusions and Perspective}

The multi-functionality problem is an artefact of wishing to isolate one function out of many. As artefacts can only be cured in an artificial way, there is no 'correct' way of solving the multi-functionality problem, even not in theory. There are, however, demands one can make to solving this problem, like that the solution should be consistent in itself, and that it should be consistent with main methodological principles (as in Guinée et al. 2002, these particularly deal with assumption of including almost no economic and technological mechanisms into the LCA).

Besides the economic allocation method, illustrated with examples in this paper, there are thus more methodological solutions to the multi-functionality possible and defensible. By focussing on economic allocation, we do not suggest that these other methods are no good. We do, however, currently consider economic allocation the best generally applicable and consistent approach fitting within modelling principles as described in the Handbook on LCA, although we still recommend to perform sensitivity analyses in addition to this.

The examples presented have helped us to establish a decision tree for handling the multi-functionality problem by economic allocation. This decision tree is with some minor adaptations also applicable to other allocation methods in this paper.

The examples can be broadened to other materials and allocation situations. We would encourage others to provide other examples and experiences and communicate these through reports and papers. We expect that these will help to further improve and refine the guidelines and decision tree for economic allocation in future.

Acknowledgements. We thank two anonymous reviewers for their constructive comments and for correcting and pointing out some errors.

\section{References}

Guinée JB (Ed.), Gorrée M, Heijungs R, Huppes G, Kleijn R, Wegener Sleeswijk A, Udo de Haes HA, de Bruijn JA, van Duin R, Huijbregts MAJ (2002): Handbook on Life Cycle Assessment: Operational Guide to the ISO Standards. Kluwer Academic Publishers. Dordrecht (Hardbound, ISBN 1-4020-0228-9; Paperback, ISBN 1-4020-0557-1; see also http://www.kap.nl/prod/b/1-4020-0228-9)

Guinée JB (2001): Handbook on Life Cycle Assessment - Operational Guide to the ISO Standards. Int J LCA 6 (5) 255

Heijungs R, Frischknecht R (1998): A Special View on the Nature of the Allocation Problem. Int J LCA 3 (6) 321-332

Heijungs R, Suh S (2002): The Computational Structure of Life Cycle Assessment. Kluwer Academic Publishers, Dordrecht

Huppes G (1993): Macro-environmental policy - principles and design. Elsevier, Amsterdam

ISO International Standard 14041 (1998E): Environmental management - Life cycle assessment - Goal and scope definition and Inventory analysis. International Organisation for Standardisation (ISO), Geneva

Koutsoyiannis A (1980): Modern microeconomics (second edition). MacMillan Press, London

Vogtländer JG, Brezet HC, Hendriks CF (2001): The Virtual Eco-Costs '99A Single LCA-Based Indicator for Sustainability and the Eco-Costs - Value Ratio (EVR) Model for Economic Allocation. Int J LCA 6 (3) 157-166

Weidema BP (2001): Avoiding co-product allocation in life-cycle assessment. J Ind Ecol 4 (3) 39-61

Werner F, Richter K (2000): Economic Allocation in LCA - A Case Study About Aluminium Window Frames. Int J LCA 5 (2) 79-83

Received: April 27th, 2003

Accepted: October 6th, 2003

OnlineFirst: October 7th, 2003 